\title{
Risk Factors for Growth of Intracranial Aneurysms: A Systematic Review and Meta-Analysis
}

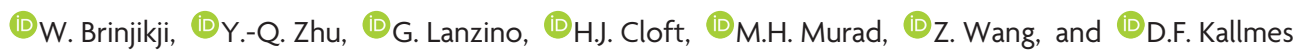

\begin{abstract}
BACKGROUND AND PURPOSE: Understanding risk factors for intracranial aneurysm growth is important for patient management. We performed a meta-analysis examining risk factors for intracranial aneurysm growth in longitudinal studies and examined the association between aneurysm growth and rupture.
\end{abstract}

MATERIALS AND METHODS: We searched the literature for longitudinal studies of patients with unruptured aneurysms. We examined the associations of demographics, multiple aneurysms, prior subarachnoid hemorrhage, family history of aneurysm or subarachnoid hemorrhage, smoking, and hypertension; and aneurysm shape, size, and location with aneurysm growth. We studied the association between aneurysm growth and rupture. A meta-analysis was performed by using a random-effects model by using summary statistics from included studies.

RESULTS: Twenty-one studies including 3954 patients with 4990 aneurysms with 13,294 aneurysm-years of follow-up were included. The overall proportion of growing aneurysms was 3.0\% per aneurysm-year $(95 \% \mathrm{Cl}, 2.0 \%-4.0 \%)$. Patient risk factors for growth included age older than 50 years (3.8\% per year versus $0.9 \%$ per year, $P<.01)$, female sex $(3.2 \%$ per year versus $1.3 \%$ per year, $P<.01)$, and smoking history (5.5\% per year versus $3.5 \%$ per year, $P<.01$ ). Characteristics associated with higher growth rates included cavernous carotid artery location (14.4\% per year), nonsaccular shape (14.7\% per year versus $5.2 \%$ per year for saccular, $P<.01)$, and aneurysm size $(P<.01)$. Aneurysm growth was associated with a rupture rate of $3.1 \%$ per year compared with $0.1 \%$ per year for stable aneurysms $(P<.01)$.

CONCLUSIONS: Observational evidence provided multiple clinical and anatomic risk factors for aneurysm growth, including age older than 50 years, female sex, smoking history, and nonsaccular shape. These findings should be considered when counseling patients regarding the natural history of unruptured intracranial aneurysms.

Ui nruptured intracranial aneurysms have a fairly high prevalence in the general population, with estimates of aneurysm prevalence ranging from $2 \%$ to $8 \% .{ }^{1,2}$ However, the incidence of subarachnoid hemorrhage is substantially lower, estimated to be $10-30$ per 100,000 per year. ${ }^{3}$ In addition to rupture, aneurysms can result in substantial morbidity secondary to cranial nerve palsies, headache, and even anxiety. ${ }^{4}$ Overall, there has been a trend toward increased treatment of unruptured intracranial aneurysms with surgical clipping and endovascular coiling. ${ }^{5}$ With im-

Received May 14, 2015; accepted after revision July 21.

From the Departments of Radiology (W.B., Y.-Q.Z., G.L., H.J.C., D.F.K.) and Neurosurgery (G.L., H.J.C., D.F.K.) and Center for Science of Healthcare Delivery (M.H.M., Z.W.), Mayo Clinic, Rochester, Minnesota.

Please address correspondence to Waleed Brinjikji, MD, Mayo Clinic, 200 First St SW, OL1-112 SMH, Rochester, MN 55905, e-mail: Brinjikji.waleed@mayo.edu; @WBrinjikji

三 Indicates article with supplemental on-line table.

http://dx.doi.org/10.3174/ajnr.A4575 provement in operative and endovascular techniques as well as postoperative care, the morbidity and mortality related to these procedures has decreased with time. ${ }^{6}$ When counseling patients with unruptured aneurysms, many practitioners discuss the risks of surgical or endovascular treatment in the context of the natural history of their aneurysms. ${ }^{4}$ Results from long-term follow-up studies, such as the International Study of Unruptured Intracranial Aneurysms, the Small Unruptured Intracranial Aneurysm Verification study (UCAS), are often used in discussing the natural history of unruptured aneurysms with patients. ${ }^{7-11}$

Risk factors for aneurysm growth are relatively understudied compared with those of aneurysm rupture. However, many longitudinal observational studies may not follow patients long enough to witness aneurysm rupture but will see aneurysm growth during their short follow-up time. In addition, aneurysms that grow on surveillance imaging are generally treated; this factor potentially decreases the rupture rate in many longitudinal studies. Because growth itself may be a risk factor for rupture, an 
understanding of the clinical and anatomic risk factors for aneurysm growth is important. ${ }^{12}$ Therefore, we performed a systematic review and meta-analysis of all published studies examining the clinical and anatomic risk factors for aneurysm growth. In addition, we performed a separate analysis to determine the rupture rate of growing aneurysms. We hypothesized that factors known to be associated with aneurysm rupture (ie, Japanese or Finnish population, hypertension, older age, increasing aneurysm size, previous $\mathrm{SAH}$, and location) would also be associated with growth.

\section{MATERIALS AND METHODS}

A comprehensive literature search of the data bases PubMed, Ovid MEDLINE, and Ovid EMBASE was designed and conducted by an experienced librarian with input from the authors. The key words, "intracranial aneurysm," "unruptured aneurysm," "aneurysm," "cerebral aneurysm," "growth," "natural history," "rupture," "longitudinal," "morbidity," “mortality," “CT," "MR imaging," and "angiography," were used in "and/or" combinations. The search included all articles published on this topic from January 1960 to November 2014. All studies with longitudinal follow-up of unruptured intracranial aneurysms reporting growth were included. Inclusion criteria were the following: 1) a series of $>10$ patients, with available data on clinical and anatomic risk factors for aneurysm growth; 2) a series with a mean or median follow-up of at least 12 months; 3) studies published in English; and 4) studies of a consecutive series of patients with unruptured aneurysms undergoing clinical and/or angiographic follow-up. Studies with $<10$ patients, published, in a language other than English, or with a mean or median follow-up of $<12$ months were excluded. Studies comparing the characteristics of ruptured and unruptured intracranial aneurysms on presentation were excluded as well. Two reviewers selected the included studies. Inconsistencies were handled by a third reviewer with final say regarding inclusion or exclusion of a given study.

For each study, we extracted the following information for risk factors for aneurysm growth: overall proportion of growing aneurysms, age (by using both 50 and 70 years as age cutoffs), ethnicity, sex, aneurysm location (ICA, MCA, anterior cerebral artery/anterior communicating artery, vertebrobasilar, and common carotid artery), posterior or anterior aneurysm location, aneurysm multiplicity, prior SAH, family history of aneurysm or SAH, hypertension, smoking, aneurysm shape (saccular, lobular, daughter sac, fusiform), saccular or nonsaccular morphology, and aneurysm size (by using 3, $5,7,10,13$, and $25 \mathrm{~mm}$ as cutoffs). In addition, we studied the association between aneurysm growth and rupture. Aneurysm size and age could not be analyzed as continuous variables because these data were obtained from summary data rather than individual patient data. We chose the most commonly used age and size categories to include the largest number of patients/aneurysms possible for this study. The definition of aneurysm growth varied by study; however, in general, "growth" was defined as an increase of at least 1-2 mm in maximum aneurysm dimension.

We also collected the following information from each study: patient-years of follow-up, aneurysm-years of follow-up, mean overall follow-up, study population, study design, outcomes reported, imaging used in follow-up, and study risk of bias. Because the included studies were uncontrolled, we modified the Newcastle-Ottawa Quality Assessment Scale to assess the risk of bias. Therefore, we assessed study risk of bias on the basis of the following questions: Did the study include all patients or consecutive patients with clinical or angiographic follow-up versus a selected sample? Were angiographic and clinical follow-up satisfactory, thus allowing ascertainment of all outcomes? Was the case definition adequate (ie, the clinical and angiographic risk factors were clearly stated)? Were outcomes well ascertained? Was the length of longitudinal follow-up sufficient to estimate aneurysm growth rates? Studies judged to be at low risk of bias were defined as those with a predefined study protocol, high rates of imaging and clinical follow-up (at least 70\% of angiographic and/or clinical follow-up during the study period), and adequate ascertainment of clinical and anatomic risk factors for growth. Studies judged to be at a high risk of bias were those that evaluated only a specific subset of patients with unruptured aneurysms (ie, specific size, location), had a lack of adequate ascertainment of clinical and anatomic risk factors for growth and/or rupture, and had low rates of angiographic or clinical follow-up.

\section{Statistical Analysis}

We estimated from each cohort the cumulative incidence (event rate) and 95\% confidence interval of the proportion of aneurysms growing per year of follow-up for individual aneurysm characteristics and per patient-year for patient/clinical characteristics. All data are reported on a per-year basis rather than a per-patient or per-aneurysm basis. Event rates for each intervention were pooled in a meta-analysis across studies by using the DerSimonian and Laird random-effects models. ${ }^{13}$ Anticipating heterogeneity between studies, we chose this model a priori because it incorporates within-study variance and between-study variance. We also extracted a $2 \times 2$ table for each studied outcome for interaction testing and calculated $P$ values for the comparisons between the previously mentioned clinical and anatomic characteristics. Meta-regression was not used in this study. Heterogeneity of treatment effect across studies was evaluated by using the $\mathrm{I}^{2}$ statistic, in which $\mathrm{I}^{2}$ $>50 \%$ suggested substantial heterogeneity. ${ }^{14}$

\section{RESULTS}

\section{Literature Review}

Our initial literature search yielded 1029 articles. Twenty-one studies reported risk factors for aneurysm growth, including 3954 patients with 4990 aneurysms with 11,000 patient-years and 13,294 aneurysm-years of follow-up.,12,15-33 Eleven of these studies reported the rupture rate of growing aneurysms. Mean patient follow-up was 4.9 years, and median was 3.2 years. The characteristics of the included studies are provided in the On-line Table. Details of our search are provided in Fig 1.

\section{Risk Factors for Aneurysm Growth}

Overall growth rate per aneurysm was $3.0 \%$ of aneurysms per aneurysm-year (95\% CI, 2.0\%-4.0\%) (Fig 2). Patient risk factors for aneurysm growth included age older than 50 years $(3.8 \%$ per year compared with $0.9 \%$ per year, $P<.01)$, female sex $(3.2 \%$ per 
year versus $1.3 \%$ per year, $P<.01$ ), and prior smoking history (5.5\% per year versus $3.5 \%$ per year, $P<.01$ ).

By location, aneurysms with the highest growth rates included cavernous carotid artery (14.4\% per year), vertebrobasilar $(3.6 \%$ per year), and MCA aneurysms (3.3\% per year). Overall, the

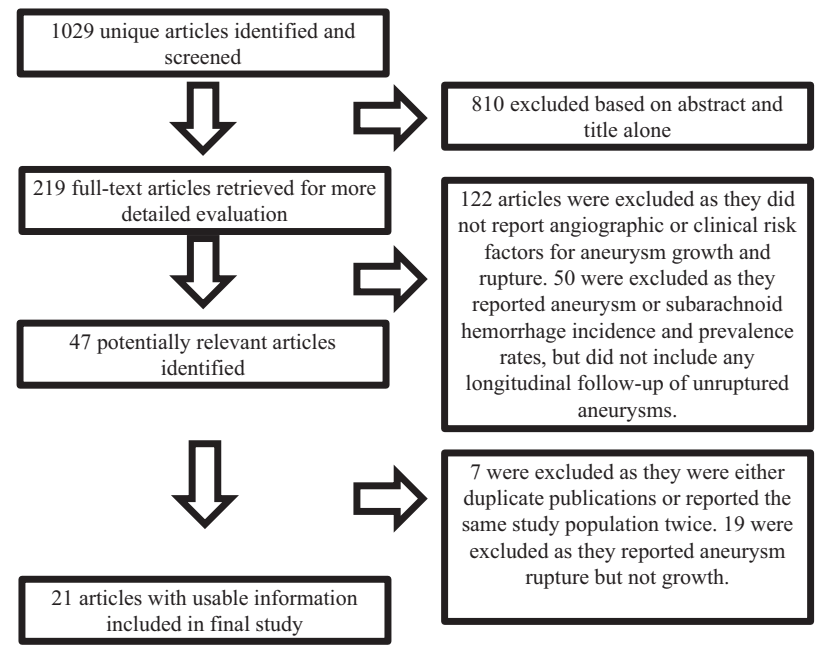

FIG 1. Flow diagram summarizing the search strategy for meta-analysis. growth rate was higher for posterior circulation aneurysms $(3.8 \%$ per year) compared with anterior circulation aneurysms $(2.7 \%$ per year, $P<.01)$. Aneurysms with nonsaccular shape had higher growth rates than saccular aneurysms $(14.7 \%$ per year versus $5.2 \%$ per year, $P<.01)$. Aneurysms of $<10 \mathrm{~mm}$ were associated with growth rates of $2.9 \%$ per year, while aneurysms of $>10 \mathrm{~mm}$ were associated with growth rates of $9.7 \%$ per year $(P<.01)$.

Aneurysm multiplicity, family history, hypertension, and prior history of SAH were not statistically associated with higher rates of aneurysm growth $(P>.05)$. These data are summarized in the Table.

\section{Aneurysm Growth and Rupture}

Ten studies examined the association between aneurysm growth and rupture. Aneurysm growth was associated with a rupture rate of $3.1 \%$ per year compared with $0.1 \%$ per year for nongrowing aneurysms $(P<.01)$.

\section{Risk of Bias}

Of the 21 studies included in our meta-analysis, 15 had a high risk of bias, 4 had a moderate risk of bias, and 2 had a low risk of bias. Studies at a high risk of bias reported higher rates of aneurysm

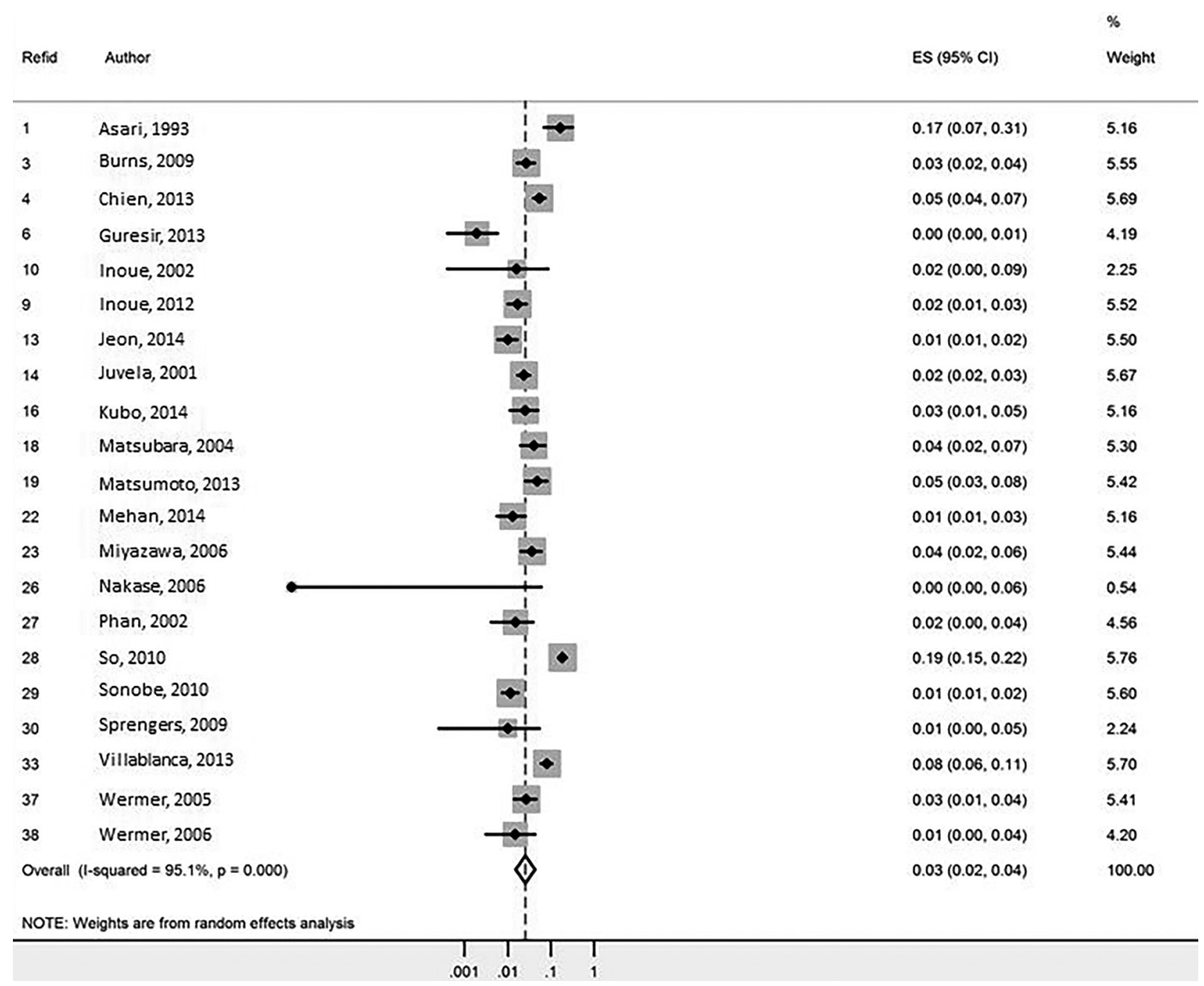

FIG 2. Forest plot for aneurysm growth meta-analysis. 
Risk factors for aneurysm growth

\begin{tabular}{|c|c|c|c|c|}
\hline & $\begin{array}{l}\text { No. of } \\
\text { Studies }\end{array}$ & $\begin{array}{c}\text { Proportion of } \\
\text { Growing Aneurysms } \\
\text { per Patient-Year } \\
(95 \% \mathrm{Cl})\end{array}$ & $\mathrm{I}^{2}$ & $\begin{array}{c}P \\
\text { Value }\end{array}$ \\
\hline Overall growth rate & 21 & $3.0(2.0-4.0)$ & 95 & - \\
\hline \multicolumn{5}{|l|}{ Age (yr) } \\
\hline 50 or younger & 6 & $0.9(0.0-24.7)$ & 93 & $<.0001$ \\
\hline 50 or older & 3 & $3.8(1.3-11.5)$ & 96 & \\
\hline 70 or younger & 5 & $2.4(0.4-16.3)$ & 96 & .04 \\
\hline 70 or older & 1 & $2.5(1.2-5.4)$ & NA & \\
\hline \multicolumn{5}{|l|}{ Population } \\
\hline Japanese & 9 & $2.7(1.5-4.7)$ & 82 & - \\
\hline Finnish & 1 & $2.4(1.7-3.3)$ & NA & - \\
\hline \multicolumn{5}{|l|}{ Sex } \\
\hline Male & 12 & $1.3(0.5-3.6)$ & 90 & $<.01$ \\
\hline Female & 12 & $3.2(1.6-6.3)$ & 95 & \\
\hline \multicolumn{5}{|l|}{ Aneurysm location } \\
\hline ICA & 13 & $2.5(1.1-5.5)$ & 92 & $<.01$ \\
\hline MCA & 13 & $3.3(1.4-7.9)$ & 87 & \\
\hline ACA/AcomA & 13 & $1.8(0.8-4.2)$ & 89 & \\
\hline VBA & 12 & $3.6(1.3-9.9)$ & 85 & \\
\hline Cavernous carotid artery & 2 & $14.4(5.1-40.2)$ & 75 & \\
\hline \multicolumn{5}{|l|}{ Anterior vs posterior } \\
\hline Anterior & 14 & $2.7(1.4-5.0)$ & 95 & $<.01$ \\
\hline Posterior & 13 & $3.8(1.5-9.9)$ & 84 & \\
\hline \multicolumn{5}{|l|}{ Multiple aneurysms } \\
\hline Yes & 13 & $2.3(1.1-4.8)$ & 85 & .80 \\
\hline No & 11 & $3.0(1.7-5.4)$ & 86 & \\
\hline \multicolumn{5}{|l|}{ Prior SAH } \\
\hline Yes & 9 & $2.2(0.7-6.8)$ & 92 & .06 \\
\hline No & 8 & $4.7(1.9-11.6)$ & 95 & \\
\hline \multicolumn{5}{|l|}{ Family history } \\
\hline Yes & 7 & $5.0(1.6-15.1)$ & 79 & .58 \\
\hline No & 7 & $3.8(1.5-9.3)$ & 97 & \\
\hline \multicolumn{5}{|l|}{ HTN } \\
\hline Yes & 11 & $3.9(1.9-8.0)$ & 92 & .88 \\
\hline No & 11 & $4.0(1.9-8.0)$ & 93 & \\
\hline \multicolumn{5}{|l|}{ Smoking } \\
\hline Yes & 12 & $5.5(3.0-9.9)$ & 81 & $<.01$ \\
\hline No & 11 & $3.5(1.7-7.1)$ & 94 & \\
\hline \multicolumn{5}{|l|}{ Shape } \\
\hline Saccular & 4 & $5.2(2.3-11.8)$ & 75 & $<.01$ \\
\hline Lobular & 2 & $15.2(5.8-40.2)$ & 0 & \\
\hline Daughter sac & 1 & $16.7(4.9-56.7)$ & NA & \\
\hline Fusiform & 1 & $13.7(6.4-29.5)$ & NA & \\
\hline \multicolumn{5}{|l|}{ Shape } \\
\hline Saccular & 4 & $5.2(2.3-11.8)$ & 75 & $<.01$ \\
\hline Nonsaccular & 4 & $14.7(8.6-25.2)$ & 0 & \\
\hline \multicolumn{5}{|l|}{ Size (mm) } \\
\hline$<3$ & 4 & $4.1(1.3-12.9)$ & 88 & $<.01$ \\
\hline$>3$ & 15 & $5.2(2.9-9.3)$ & 87 & \\
\hline$<5$ & 9 & $2.3(1.2-4.2)$ & 89 & $<.01$ \\
\hline$>5$ & 13 & $6.5(3.6-12.0)$ & 84 & \\
\hline$<7$ & 11 & $2.5(1.5-4.1)$ & 90 & $<.01$ \\
\hline$>7$ & 10 & $9.2(4.1-20.6)$ & 84 & \\
\hline$<10$ & 15 & $2.9(1.6-5.2)$ & 96 & $<.01$ \\
\hline$>10$ & 10 & $9.7(4.0-23.8)$ & 81 & \\
\hline$<13$ & 15 & $3.0(1.6-5.3)$ & 96 & $<.01$ \\
\hline$>13$ & 5 & $8.1(1.8-36.1)$ & 83 & \\
\hline \multicolumn{5}{|l|}{ Study risk of bias } \\
\hline High & 15 & $2.9(1.6-5.6)$ & 95 & $<.01$ \\
\hline Medium & 4 & $1.7(0.4-7.2)$ & 92 & \\
\hline Low & 2 & $1.7(0.8-3.4)$ & 86 & \\
\hline
\end{tabular}

Note:-AcomA indicates anterior communicating artery; VBA, vertebrobasilar artery; HTN, hypertension; ACA, anterior cerebral artery; NA, not applicable.

growth $(2.9 \%$ per year) compared with those with a low risk of bias ( $1.7 \%$ per year).

\section{DISCUSSION}

This meta-analysis of 21 longitudinal studies examining the natural history of unruptured aneurysms highlights a number of im- portant risk factors for aneurysm growth. Overall growth rates of $2.5 \%$ of aneurysms per year are not negligible. Risk factors found to be statistically associated with aneurysm growth included larger aneurysm size, posterior circulation location, irregular aneurysm shape, smoking, and female sex. Aneurysm growth was in itself a risk factor for rupture with growing aneurysms being $>30$ times as likely to rupture compared with stable aneurysms. These findings are noteworthy because they highlight important clinical and anatomic risk factors for progression of intracranial aneurysms that can be used in counseling patients with unruptured aneurysms. Risk factors for aneurysm growth have not been as extensively studied as those for aneurysm rupture. This metaanalysis highlights the fact that aneurysm growth is not uncommon; and in the case of larger and irregularly shaped aneurysms and aneurysms located in the cavernous carotid artery, growth rates are rather high.

Overall, large previous studies have demonstrated that annual aneurysm growth rates hover around $1.5 \%-2.5 \%$ of aneurysms/ year, similar to our findings. ${ }^{12,20,31,34}$ A number of factors have been reported associated with aneurysm growth, including aneurysm size, location at a bifurcation or posterior circulation, young age, hypertension, smoking, aneurysm multiplicity, and aneurysm lobulation. ${ }^{12,16,18,21,31}$ Our meta-analysis of nearly 4000 patients found that growth was associated with increasing age, female sex, smoking, irregular aneurysm shape, location in the posterior circulation, cavernous carotid artery or MCA bifurcation, and larger aneurysm size.

The rupture rate of growing aneurysms varies substantially across studies. In a study of 1002 patients with 1325 unruptured aneurysms, Inoue et $\mathrm{al}^{20}$ found that the annual rupture risk after aneurysm growth was $18.5 \%$ /person-year. Mehan et al ${ }^{12}$ found that aneurysm growth was associated with an odds ratio of 55.9 for rupture on a multivariate analysis. Villablanca et $\mathrm{al}^{31}$ found that annual rupture rates were $>10$ times higher in growing compared with nongrowing aneurysms. Juvela et $\mathrm{al}^{22}$ also demonstrated a strong association between aneurysm growth and rupture. The series of Juvela et al, which has the longest follow-up of any population-based study on the natural history of unruptured aneurysms, demonstrated that $45 \%$ of aneurysms undergoing follow-up had some growth of $>1 \mathrm{~mm}$ during the lifetime of the patient. Of these, $66 \%$ ruptured. ${ }^{22}$ In our meta-analysis, growing aneurysms were $>30$ times more likely to rupture than stable ones, and the overall rupture rate of these aneurysms was 3.1\% per year.

Understanding factors associated with aneurysm growth is also important because imaging surveillance of intracranial aneurysms is based on the principle that aneurysms that grow or change morphology are less stable and thus more prone to rupture. ${ }^{4}$ Progression of the aneurysm is generally considered an indication to treat because growing aneurysms are known to be associated with aneurysm rupture. ${ }^{35}$ Understanding factors associated with aneurysm growth could help in determining which subset of aneurysms deserve the closest follow-up. For example, in our study, aneurysms with daughter sacs or lobulations had a $14.7 \%$ growth rate per year, while the overall aneurysm growth rate was $2.5 \%$ per year. These findings would suggest that such aneurysms may require more regular imaging follow-up to detect 
growth to allow intervention before future rupture. Ultimately, further studies are needed to determine the best screening decisions for high-risk aneurysms.

Risk factors for aneurysm rupture have been more extensively studied than aneurysm growth due to the substantial morbidity and mortality rates associated with aneurysmal subarachnoid hemorrhage. ${ }^{4}$ A number of large longitudinal studies on the risk factors of aneurysmal rupture have been performed, which have enhanced our understanding of the natural history of unruptured aneurysms. $^{7,9,10,22,33,36-39}$ Overall rupture rates in these studies range from $1 \%$ to $1.4 \%$ per year. ${ }^{9,10,36,37}$ Clinical risk factors for aneurysm rupture in these studies included hypertension, smoking, aneurysm multiplicity, prior history of SAH, family history, and female sex. ${ }^{22}$ Anatomic risk factors included increased aneurysm size, the presence of a daughter sac, and posterior circulation location. ${ }^{9,36}$ These factors are similar to those seen in our metaanalysis of aneurysm growth.

A number of models have been proposed to study the risks of aneurysm rupture. The recently published PHASES score is based on data from several large population studies comprising 8382 patients with 10,272 aneurysms. ${ }^{8}$ Risk factors for aneurysm rupture in this risk score include Japanese or Finnish descent, hypertension, age older than 70 years, larger aneurysm size, prior SAH, and MCA/anterior cerebral artery/posterior communicating artery/posterior circulation aneurysm location. A higher PHASES score is strongly associated with a higher risk of rupture. Our study highlights a number of variables that were strongly associated with aneurysm growth that were not included in the original PHASES score, including irregular aneurysm shape (ie, lobulation, daughter sac, fusiform), female sex, and smoking. Furthermore, aneurysm growth was found to be a strong predictor of rupture. One recently published consensus study by Etminan et $\mathrm{al}^{35}$ proposed a model for assessing treatment decisions for unruptured aneurysms that combined variables, including clinical characteristics, family history, and aneurysm characteristics. This study highlighted factors such as aneurysm growth, lobulation, and smoking history into their model as factors that would sway the decision toward treatment rather than observation. ${ }^{35}$ Our study lends further evidence to support the conclusions of this consensus group.

\section{Strengths and Limitations}

The strengths of our study include following an a priori established protocol, the comprehensive literature search that involved multiple data bases, and the process of study selection performed by independent reviewers. The main limitation of this analysis is the lack of individual patient data, which makes prognostic analysis subject to confounding and ecologic bias. In addition, 15/21 studies having a high risk of bias further limits our results. Furthermore, many studies differed in their methods of classifications of aneurysm size, location, shape, definition of family history, and smoking history. Aneurysm growth was assessed with various imaging modalities, including CTA, DSA, and MRA, which could introduce some error or bias. In addition, studies had variable thresholds for determining growth of the aneurysm. Aneurysm measurements could vary substantially on the basis of software packages and imaging modalities used. In addition, there is the possibility of inter- and intraobserver variability in assessing aneurysm growth. There are no validated tools to evaluate the methodologic quality of noncomparative series. Publication bias is very likely in the setting of observational studies. The results of this study are further biased because larger aneurysms are more likely to be treated than smaller aneurysms; this treatment choice clouds our understanding of the natural history of these lesions. The results of our study may be biased because they are based on only studies that reported risk factors for aneurysm growth. Last, uniform assessment and reporting of complications in a standardized fashion were lacking. Nevertheless, this meta-analysis provides useful prognostic data to share with patients and families when assessing the natural history of intracranial aneurysms.

\section{CONCLUSIONS}

Overall growth rates of intracranial aneurysms are not negligible. Risk factors for the growth of intracranial aneurysms included nonsaccular aneurysm shape, larger aneurysm size, hypertension, and female sex. Aneurysm growth is significantly associated with rupture as well. These findings should be considered when counseling patients regarding the natural history of intracranial aneurysms.

Disclosures: Giuseppe Lanzino-UNRELATED: Consultancy: Covidien.* David F. Kallmes_UNRELATED: Board Membership: GE Healthcare,* Comments: Cost-Effectiveness Board; Consultancy: ev3/Covidien/Medtronic, ${ }^{*}$ Comments: clinical trial planning and implementation; Grants/Grants Pending: ev3/Covidien/Medtronic,* Codman, ${ }^{*}$ Sequent Medical, ${ }^{*}$ NeuroSigma, ${ }^{\star}$ Surmodics, ${ }^{*}$ MicroVention, ${ }^{\star}$ Comments: research support for preclinical and clinical studies; Royalties: University of Virginia patent foundation (Spinal Fusion); Travel/Accommodations/Meeting Expenses Unrelated to Activities Listed: ev3/Covidien/Medtronic, ${ }^{*}$ Comments: travel to present at an FDA panel meeting. ${ }^{*}$ Money paid to the institution.

\section{REFERENCES}

1. Li MH, Chen SW, Li YD, et al. Prevalence of unruptured cerebral aneurysms in Chinese adults aged 35 to 75 years: a cross-sectional study. Ann Intern Med 2013;159:514-21 CrossRef Medline

2. Vlak MH, Algra A, Brandenburg R, et al. Prevalence of unruptured intracranial aneurysms, with emphasis on sex, age, comorbidity, country, and time period: a systematic review and meta-analysis. Lancet Neurol 2011;10:626-36 CrossRef Medline

3. Ziemba-Davis M, Bohnstedt BN, Payner TD, et al. Incidence, epidemiology, and treatment of aneurysmal subarachnoid hemorrhage in 12 Midwest communities. J Stroke Cerebrovasc Dis 2014;23: 1073-82 CrossRef Medline

4. Brown RD Jr, Broderick JP. Unruptured intracranial aneurysms: epidemiology, natural history, management options, and familial screening. Lancet Neurol 2014;13:393-404 CrossRef Medline

5. Brinjikji W, Rabinstein AA, Lanzino G, et al. Effect of age on outcomes of treatment of unruptured cerebral aneurysms: a study of the National Inpatient Sample 2001-2008. Stroke 2011;42:1320-24 CrossRef Medline

6. Brinjikji W, Rabinstein AA, Lanzino G, et al. Patient outcomes are better for unruptured cerebral aneurysms treated at centers that preferentially treat with endovascular coiling: a study of the National Inpatient Sample 2001-2007. AJNR Am J Neuroradiol 2011; 32:1065-70 CrossRef Medline

7. Wiebers DO, Whisnant JP, Huston J 3rd, et al; International Study of Unruptured Intracranial Aneurysms Investigators. Unruptured intracranial aneurysms: natural history, clinical outcome, and risks of surgical and endovascular treatment. Lancet 2003;362:103-10 CrossRef Medline

8. Greving JP, Wermer MJ, Brown RD Jr, et al. Development of the PHASES score for prediction of risk of rupture of intracranial 
aneurysms: a pooled analysis of six prospective cohort studies. Lancet Neurol 2014;13:59-66 CrossRef Medline

9. Sonobe M, Yamazaki T, Yonekura M, et al. Small unruptured intracranial aneurysm verification study: SUAVe study, Japan. Stroke 2010;41:1969-77 CrossRef Medline

10. Ishibashi T, Murayama $\mathrm{Y}$, Urashima $\mathrm{M}$, et al. Unruptured intracranial aneurysms: incidence of rupture and risk factors. Stroke 2009; 40:313-16 CrossRef Medline

11. Bonares MJ, de Oliveira Manoel AL, Macdonald RL, et al. Behavioral profile of unruptured intracranial aneurysms: a systematic review. Ann Clin Transl Neurol 2014;3:220-32 Medline

12. Mehan WA Jr, Romero JM, Hirsch JA, et al. Unruptured intracranial aneurysms conservatively followed with serial CT angiography: could morphology and growth predict rupture? J Neurointerv Surg 2014;6:761-66 CrossRef Medline

13. DerSimonian R, Laird N. Meta-analysis in clinical trials. Control Clin Trials 1986;7:177-88 CrossRef Medline

14. Higgins JP, Thompson SG, Deeks JJ, et al. Measuring inconsistency in meta-analyses. BMJ 2003;327:557-60 CrossRef Medline

15. Asari S, Ohmoto T. Natural history and risk factors of unruptured cerebral aneurysms. Clin Neurol Neurosurg 1993;95:205-14 CrossRef Medline

16. Burns JD, Huston J 3rd, Layton KF, et al. Intracranial aneurysm enlargement on serial magnetic resonance angiography: frequency and risk factors. Stroke 2009;40:406-11 CrossRef Medline

17. Chien A, Liang F, Sayre J, et al. Enlargement of small, asymptomatic, unruptured intracranial aneurysms in patients with no history of subarachnoid hemorrhage: the different factors related to the growth of single and multiple aneurysms. J Neurosurg 2013;119: 190-97 CrossRef Medline

18. Güresir E, Vatter H, Schuss P, et al. Natural history of small unruptured anterior circulation aneurysms: a prospective cohort study. Stroke 2013;44:3027-31 CrossRef Medline

19. Inoue T. Treatment of incidental unruptured aneurysms. Acta Neurochir Suppl 2002;82:11-15 Medline

20. Inoue $\mathrm{T}$, Shimizu $\mathrm{H}$, Fujimura $\mathrm{M}$, et al. Annual rupture risk of growing unruptured cerebral aneurysms detected by magnetic resonance angiography. J Neurosurg 2012;117:20-25 CrossRef Medline

21. Jeon JS, Ahn JH, Huh W, et al. A retrospective analysis on the natural history of incidental small paraclinoid unruptured aneurysm. J Neurol Neurosurg Psychiatry 2014;85:289-94 CrossRef Medline

22. Juvela S, Poussa K, Porras M. Factors affecting formation and growth of intracranial aneurysms: a long-term follow-up study. Stroke 2001;32:485-91 CrossRef Medline

23. Kubo Y, Koji T, Kashimura H, et al. Female sex as a risk factor for the growth of asymptomatic unruptured cerebral saccular aneurysms in elderly patients. J Neurosurg 2014;121:599-604 CrossRef Medline

24. Matsubara S, Hadeishi H, Suzuki A, et al. Incidence and risk factors for the growth of unruptured cerebral aneurysms: observation using serial computerized tomography angiography. J Neurosurg 2004;101:908-14 CrossRef Medline

25. Matsumoto K, Oshino S, Sasaki M, et al. Incidence of growth and rupture of unruptured intracranial aneurysms followed by serial MRA. Acta Neurochir (Wien) 2013;155:211-16 CrossRef Medline

26. Miyazawa N, Akiyama I, Yamagata Z. Risk factors for growth of unruptured intracranial aneurysms: follow-up study by serial 0.5-T magnetic resonance angiography. Neurosurgery 2006;58:1047-53; discussion 1047-53 CrossRef Medline

27. Nakase H, Shin Y, Kanemoto Y, et al. Long-term outcome of unruptured giant cerebral aneurysms. Neurol Med Chir (Tokyo) 2006;46: 379-84; discussion 384-86 CrossRef Medline

28. Phan TG, Huston J 3rd, Brown RD Jr, et al. Intracranial saccular aneurysm enlargement determined using serial magnetic resonance angiography. J Neurosurg 2002;97:1023-28 CrossRef Medline

29. So TY, Dowling R, Mitchell PJ, et al. Risk of growth in unruptured intracranial aneurysms: a retrospective analysis. J Clin Neurosci 2010;17:29-33 CrossRef Medline

30. Sprengers ME, van Rooij WJ, Sluzewski M, et al. MR angiography follow-up 5 years after coiling: frequency of new aneurysms and enlargement of untreated aneurysms. AJNR Am J Neuroradiol 2009; 30:303-07 Medline

31. Villablanca JP, Duckwiler GR, Jahan R, et al. Natural history of asymptomatic unruptured cerebral aneurysms evaluated at CT angiography: growth and rupture incidence and correlation with epidemiologic risk factors. Radiology 2013;269:258-65 CrossRef Medline

32. Wermer MJ, van der Schaaf IC, Velthuis BK, et al; ASTRA Study Group. Follow-up screening after subarachnoid haemorrhage: frequency and determinants of new aneurysms and enlargement of existing aneurysms. Brain 2005;128:2421-29 CrossRef Medline

33. Wermer MJ, van der Schaaf IC, Velthuis BK, et al. Yield of short-term follow-up CT/MR angiography for small aneurysms detected at screening. Stroke 2006;37:414-18 CrossRef Medline

34. Juvela S, Poussa K, Lehto H, et al. Natural history of unruptured intracranial aneurysms: a long-term follow-up study. Stroke 2013; 44:2414-21 CrossRef Medline

35. Etminan N, Beseoglu K, Barrow DL, et al. Multidisciplinary consensus on assessment of unruptured intracranial aneurysms: proposal of an international research group. Stroke 2014;45:1523-30 CrossRef Medline

36. Morita A, Kirino T, Hashi K, et al; UCAS Japan Investigators. The natural course of unruptured cerebral aneurysms in a Japanese cohort. N Engl J Med 2012;366:2474-82 CrossRef Medline

37. International Study of Unruptured Intracranial Aneurysms Investigators. Unruptured intracranial aneurysms: risk of rupture and risks of surgical intervention. $N$ Engl J Med 1998;339:1725-33 CrossRef Medline

38. Wiebers DO, Whisnant JP, Sundt TM Jr, et al. The significance of unruptured intracranial saccular aneurysms. J Neurosurg 1987;66: 23-29 CrossRef Medline

39. Wiebers DO, Whisnant JP, O'Fallon WM. The natural history of unruptured intracranial aneurysms. N Engl J Med 1981;304:696-98 CrossRef Medline 